DOI: 10.12957/demetra.2015.20084

\title{
Nova chamada para publicação de artigos dedicados ao tema "Alimentação, Corpo, Gênero e Subjetividade"
}

\section{New call for papers on the theme "Food, Body, Gender and Subjectivity"}

Neste último número de 2015, registramos alguns acontecimentos importantes que marcaram nossa trajetória e nossos esforços na consolidação do campo da Alimentação e Nutrição no Brasil como espaço caracteristicamente interdisciplinar.

Alcançamos todas as metas editoriais que nos colocamos: a periodicidade está em dia; publicamos quatro números no ano; há 20 artigos no último número. Em termos numéricos, chegamos ao patamar exigido para indexação em bases de dados internacionais consideradas pelas principais agências de fomento brasileiras como referência para cálculo de indicadores de circulação no campo da ciência. E 2016 será o ano em que daremos início aos movimentos para solicitar a inserção de nosso periódico nesses espaços.

Esse movimento está sendo possível, em especial, por conta da crescente presença de pesquisadores em programas de pós-graduação, juntamente com seus orientandos, como autores de artigos em nossa revista. Hoje, Demetra é a segunda revista brasileira no campo alimentarnutricional mais utilizada para publicação de artigos por pesquisadores dos programas de pósgraduação inseridos na área de avaliação "Nutrição" da CAPES.

Os pesquisadores do campo alimentar-nutricional estão apostando na revista, investindo em sua consolidação, vendo nela um caminho a ser trilhado. É um importante reconhecimento do nosso trabalho!

Além disso, a forte presença de trabalhos oriundos de outros campos, como as Humanidades, fica patente no último número temático voltado para "Diálogos no campo da Antropologia da Alimentação". Registramos a presença de trabalhos oriundos de todo o território nacional e de outros países da América Latina e Europa, demonstrando a ampliação do escopo geográfico de alcance do periódico. 
Seguindo nessa linha, que tem se mostrado exitosa, anunciamos a chamada para novo número temático a ser publicado em 2016: "Alimentação, Corpo, Gênero e Subjetividade”. Esta iniciativa é fruto das reflexões gestadas no âmbito dos programas de pós-graduação em Alimentação, Nutrição e Saúde, da UERJ, e em Ensino em Biociência e Saúde, do Instituto Oswaldo Cruz da Fundação Oswaldo Cruz (IOC-FIOCRUZ), por meio de intercâmbio de seus docentes e oferta de disciplina sobre a temática no ano de 2015 .

Já se pode constatar o crescente interesse acadêmico pelos estudos culturais, tanto sobre Alimentação quanto sobre Corpo e Gênero, na medida em que estas categorias expressam grande potencial na análise dos modos de funcionamento da sociedade. Elas têm sido abordadas isoladamente em campos distintos do saber, e sua integração é ainda pouco comum no âmbito acadêmico, sobretudo na saúde. Portanto, ainda permanece como um desafio para as pesquisas em Alimentação e Nutrição o acolhimento de diferentes perspectivas analíticas (sociológicas, antropológicas, históricas, psi, etc.) que favoreçam a associação entre estas fecundas categorias.

O novo número temático focalizará as relações entre Alimentação, Corpo, Gênero e Subjetividade como construções sociais, que perpassam não só a experiência de vida cotidiana, mas também os modos de fazer ciência relacionados ao desenvolvimento científico e tecnológico em saúde nos processos envolvendo alimentação, nutrição e saúde, passíveis de análises a partir de diferentes enfoques.

Este esforço se propõe a reunir trabalhos de pesquisa acerca das possíveis interfaces, entre um ou mais destes termos interligados, tendo em vista a incidência dos nexos entre corpo, relações de gênero e subjetividade no cotidiano da alimentação, e em práticas de saúde, que se produzem e se elaboram (e reelaboram) em diferentes cenários sociais e culturais na sociedade contemporânea.

Nesta direção, consideramos o quanto o entrelaçamento entre alimentação, ciência, tecnologias diversificadas e processos de subjetivação, em sentidos amplos, é perpassado por tensões e merece atenção da produção acadêmica. Almejamos destacar na conjugação desses termos, configurados historicamente como dispositivos de produção de verdades sobre si e os outros, como já apontado pela literatura antropológica e sociológica, a existência de significativas diferenças relativas ao gênero nos mais variados processos de intervenção nos corpos.

Poderão integrar esta iniciativa pesquisas empíricas e/ou teóricas dedicadas ao tema, sobretudo as que destacam, no agenciamento pelos sujeitos (intervenções no corpo, biotecnologia, medicalização, políticas da vida, práticas religiosas - enfim, variadas estratégias de produção de sentidos em interface, ou não, com a biomedicina, etc.), a problemática do corpo gendrificado como modelador da subjetividade e de parte da produção do conhecimento científico. 
São bem-vindas pesquisas que discutam o caráter social e cultural da alimentação em termos de normatizações, regulações e/ou naturalizações do corpo com implicações para a existência individual e coletiva, a saber: concepções e práticas que veiculam imagens produtoras de estigma e/ou preconceito com referência aos corpos femininos/masculinos/trans e às diversidades sexuais; idealizações do corpo (obesidade/anorexia); análises de intervenções biomédicas e/ou tecnológicas e medicalização do corpo (medicamentos, estéticas, dietéticas em seus usos lícitos/ilícitos) em sua dimensão de gênero; legislações/normativas, políticas e suas repercussões nas experiências subjetivas. Todos estes aspectos poderão ser contemplados em diferentes cenários de pesquisa, incluindo a produção midiática, cinematográfica e as artes. Serão também acolhidos trabalhos que abordem a produção do conhecimento científico nos campos focalizados, bem como a difusão da temática em diferentes âmbitos da sociedade.

Temos como editores convidados Eliane Portes Vargas, da Fundação Oswaldo Cruz; Luciane da Costa Moás, da Universidade Federal Rural do Rio de Janeiro; e Fabiana Bom Kraemer e Francisco Romão Ferreira, ambos da Universidade do Estado do Rio de Janeiro.

Mantendo a política editorial da revista, receberemos artigos e resenhas que façam análise crítica de livros recentes e relacionados ao tema. Os interessados devem encaminhar suas contribuições em inglês, português ou espanhol até 15 de março de 2016. A submissão deverá ser efetuada na página da nossa revista, através do link http://www.e-publicacoes.uerj.br/index.php/demetra/about/ submissions\#onlineSubmissions, informando seu direcionamento para a seção "Artigos Temáticos". Ademais, a comunicação aos editores deverá mencionar a chamada temática sobre "Alimentação, Corpo, Gênero e Subjetividade”. Dúvidas podem ser sanadas pelos e-mails demetra.uerj@gmail. com ou demetra@uerj.br.

Encerramos, assim, mais um ano de atividades exitosas e queremos agradecer à equipe editorial, aos autores e leitores. A todos, nossos cumprimentos, com os votos de Boas Festas e de muitas realizações em 2016 !

Shirley Donizete Prado, Fabiana Bom Kraemer, Francisco Romão Ferreira, Eliane Portes Vargas e Luciane da Costa Moás 
